\title{
PERENCANAAN STRATEGIS SISTEM INFORMASI UNTUK MENINGKATKAN PROSES BISNIS PERUSAHAAN FARMASI
}

\author{
Julia Ratnawulan Skawanti ${ }^{1)}$ \\ 1) Sekolah Tinggi Pariwisata Bogor, Indonesia \\ Corresponding Author: juliaratnawulan@yahoo.co.id
}

Article history: received 30 September 2018; revised 7 Desember 2018; accepted 15 Desember 2018

\begin{abstract}
Abstrak
Kompetisi yang ketat di dunia usaha saat ini, menuntut perusahaan untuk melakukan terobosan dan inovasi baru serta menggunakan seluruh sarana dan teknologi yang tersedia agar dapat mempertahankan pasar dan konsumen yang dimiliki. Sistem informasi menjadi bagian penting dari perusahan sebagai penunjang kinerjanya. Perusahaan yang bergerak dibidang farmasi selalu berusaha untuk meningkatkan kemampuan bersaing. Penelitian dilakukan untuk membuat perencanaan strategi sistem dan teknologi informasi yang dapat mendukung proses bisnis perusahaan. Metode penelitian dilakukan dengan cara wawancara, kuesioner, observasi dan studi pustaka. Analisis strategi menggunakan metode analisis PEST, SWOT, BSC, Value Chain dan CSF. Adapun perencanaan strategi menggunakan Tahapan Kerangka Kerja PSSI versi Ward and Peppard. Hasil yang dicapai adalah kerangka perencanaan strategi yang terintegrasi sehingga memudahkan mengelola sumberdaya untuk menghasilkan informasi yang akurat dan dapat digunakan secara bersama oleh semua pihak. Kesimpulan penelitian adalah membangun sistem informasi berbasis komputer yang dapat memdukung proses bisnis.
\end{abstract}

Keywords : perencanaan strategis informasi, sistem informasi, SWOT, BSC, CSF

\begin{abstract}
Intense competition in the business world today, requires companies to make breakthroughs and new innovations and use all available facilities and technology in order to maintain the market and consumers. Information systems become an important part of the company to support its performance. Companies engaged in pharmaceuticals are always trying to improve their competitiveness. The research was conducted to make a system strategy planning and information technology that can support the company's business processes. The research method was conducted by interview, questionnaire, observation and literature study. Strategy analysis uses the PEST, SWOT, BSC, Value Chain and CSF analysis methods. As for strategic planning using Ward and Peppard's PSSI Framework Phase. The results achieved are an integrated strategic planning framework that makes it easy to manage resources to produce accurate information and can be shared by all parties. The conclusion of the research is to build a computer-based information system that can support business processes.
\end{abstract}

Keywords : information strategic planning, information systems, SWOT, BSC, CSF

\section{Pendahuluan}

Persaingan yang ketat dalam dunia usaha terutama perusahaan farmasi mengharuskan perusahaan selalu melakukan perubahan dan inovasi agar kelangsungan usaha tetap terjaga dengan baik. Banyak perusahaan farmasi di Indonesia sudah menggunakan proses GMP (Good Manufacturing Product) serta memperoleh ISO. Di era informasi saat ini perusahaan dituntut untuk dapat mengikuti perubahan - perubahan yang terjadi dalam berbagai bidang, terutama 
bidang yang berhubungan dengan keunggulan bersaing (competitive) diperoleh dengan menerapkan strategi offensive, salah satunya adalah dengan perencanaan strategis perusahaan atau organisasi perlu didukung dengan adanya perencanaan strategis sistem informasi untuk memperoleh keuntungan (profitability) yang terus menerus.

Penerapan sistem informasi secara keseluruhan tidak terlepas dari setiap penguasaan data dan informasi oleh setiap bagian yang terlibat. Data yang dikuasai haruslah lengkap, tepat dan terbaru. Oleh karena itu setiap bagian harus memiliki sistem informasi yang mampu menyimpan, memproses dan menyajikan data dan informasi secara lengkap, akurat dan terbaru. Dari setiap sistem-sistem yang sudah ada tersebut maka dapat diintegrasikan menjadi sistem informasi perusahaan (secara keseluruhan) sehingga diharapkan perusahaan mampu menjalankan proses bisnisnya secara professional melalui peningkatan efisiensi dan kinerja.

Masalah yang timbul dan menjadi perhatian utama penelitian ini antara lain Sistem informasi (SI) apa yang sudah diterapkan untuk meningkatkan efisiensi dan efektifitas perusahaan, kebutuhan SI apa yang mendukung visi, misi dan tujuan perusahaan, bagaimana tahapan aplikasi portofolio yang akan dibangun serta bagaimana hasil evaluasi dari penerapan SI yang sudah diterapkan. Tujuan penelitian ini antara lain mampu mengembangkan sistem yang dapat meningkatkan efektifitas proses bisnis dari setiap proses yang ada dalam perusahaan, meningkatkan efisiensi perusahaan dalam rangka menghadapi pesaing serta memberikan kemudahan komunikasi antar bagian dalam organisasi. Proses bisnis yang akan dibahas meliputi efisiensi biaya operasional, integrasi SI keuangan dan SI kepegawaian, pemanfaatan database secara maksimal bagi pengembangan omset perusahaan serta program punishment and reward bagi sumber daya manusianya.

\section{Metode Penelitian}

Secara umum Sistem informasi dapat didefinisikan sebagai suatu sistem di dalam suatu organisasi yang merupakan kombinasi dari orang-orang, fasilitas, teknologi, media prosedurprosedur dan pengendalian yang ditujukan untuk mendapatkan jalur komunikasi penting, memproses tipe transaksi rutin tertentu, memberi sinyal kepada manajemen dan yang lainnya terhadap kejadian-kejadian internal dan eksternal yang penting dan menyediakan suatu dasar informasi untuk pengambilan keputusan. Dalam rangka mengelola sistem informasi dan teknologi informasi (SI/IT) strategis, akan sangat membantu untuk memahami bagaimana peran dari teknologi berbasis SI yang telah berkembang dalam organisasi.

Menurut Ward and Peppard [1] dalam buku Strategic Planning for Information System, sistem Informasi dan teknologi informasi sering dianggap sebagai hal yang sama. Hal ini harus dihindari apabila ingin membangun sebuah strategi SI/IT. Teknologi informasi berhubungan dengan teknologi yang dipakai pada sebuah perusahaan, seperti halnya hardware, software dan network. Teknologi informasi memfasilitasi pencarian data, pemrosesan data, penyimpanan data dan pembagian informasi dalam bentuk digital. Sistem Informasi sebagai cara bagi orang dan organisasi untuk memaksimalkan penggunaan teknologi untuk mengumpulkan, memproseskan dan menggunakan informasi tersebut.

Perencanaan Strategis Sistem Informasi (Strategic Information Sistem Planning / SISP) digunakan untuk mendukung strategi bisnis organisasi agar mampu mencapai tujuan bisnisnya dengan lebih cepat. Kemampuan tersebut terkait langsung dengan bagaimana organisasi memilih strategi, aplikasi dan kebijakan organisasi yang tepat dengan berfokus pada SI/TI.

Aalisis SWOT [2] adalah identifikasi berbagai faktor secara sistimatis untuk merumuskan strategi perusahaan. Analisis ini didasarkan pada logika yang dapat dimaksimalkan kekuatan (Strenghts) dan peluang (Opportunities), namun secara bersamaan dapat meminimalkan kelemahan (Weaknesses) dan ancaman (Threats). Proses pengambilan keputusan strategis selalu berkaitan dengan pengembangan misi, tujuan, strategi dan kebijakan perusahaan. Dengan demikian pencanaan strategis harus menganalisis faktor-faktor strategis perusahaan (kekuatan, peluang, kelemahan dan ancaman) dalam kondisi yang ada saat ini Sebuah perusahaan tidak selalu harus mengejar peluang yang menguntungkan karena dengan mengembangkan competitive advantage, ada kesempatan yang lebih baik untuk meraih kesuksesan dengan cara mengidentifikasi sebuah kekuatan dan kesempatan mendatang. Untuk mengembangkan strategi yang mempertimbangkan profil SWOT. Menurut Ward dan Peppard analisis PEST adalah analisis terhadap lingkungan eksternal bisnis yang meliputi bidang politik, ekonomi, sosial dan teknologi. PEST digunakan untuk menilai pasar dari suatu unit bisnis atau 
unit organisasi. Arah analisa PEST adalah kerangka untuk menilai sebuah situasi, dan menilai strategi atau posisi, arah perusahaan, rencana pemasaran, atau ide.

Balanced Scorecard (BSC), saat ini, Balanced Scorecard [3] tidak hanya digunakan dalam pengukuran kinerja, tetapi sebagai pendekatan dalam menyusun rencana strategis. Balanced Scorecard merupakan suatu kerangka kerja yang menerjemahkan visi dan misi perusahaan kedalam strategi yang diimplementasikan pada tujuan dan ukuran. Ukuran dalam Balance Scorecard dibagi menjadi empat perspektif yaitu Perspektif Keuangan (Financial Perspective), Perspektif Pelanggan (Customer Perspective), Perspektif Proses bisnis internal (Internal Business Processes Perspective) dan Perspektif Pembelajaran dan pertumbuhan (Learning And Growth Perspective).

Critical Success Factor (CSF) [5] merupakan faktor yang sangat berpengaruh terhadap kemampuan perusahaan dalam mencapai sasarannya. Ward dan Peppard merujuk pada Rockart mendefinisikan CSF sebagai area tertentu dalam perusahaan, dimana jika hasil dari area tersebut memuaskan, maka akan menjamin keberhasilan perusahaan dalam bersaing. CSF merupakan pendekatan paling efektif untuk membantu mengidentifikasikan informasi apa yang dibutuhkan organisasi atau perusahaan. Rockart memperkenalkan dua tahap dalam CSF yaitu, wawancara berbasis metode yang dimulai dengan diskusi tentang tujuan seorang eksekutif dan CSF yang mendasarinya, diikuti dengan pengembangan tindakan CSF.

\section{Hasil dan Pembahasan}

\subsection{Analisis SWOT}

Analisa ini didasarkan pada logika yang dapat memaksimalkan kekuatan dan peluang namun secara bersamaan dapat meminimalkan kelemahan dan ancaman. Matrik SWOT memberikan gambaran interaksi antara internal dan eksternal yang kemudian menghasilkan strategi-strategi dari hasil interaksi tersebut. Strategi terbagi ke dalam empat bagian yaitu:

1. Strategi SO : menggunakan kekuatan dan memanfaatkan peluang

2. Strategi WO : menggunakan kelemahan dan memanfaatkan peluang

3. Strategi ST : menggunakan kekuatan dan mengatasi kelemahan

4. Strategi WT : meminimalkan kelemahan dan menghindari ancaman Untuk lebih jelasnya dapat dilihat pada Tabel 1 Matrik SWOT berikut:

Tabel 1.Matriks SWOT

\begin{tabular}{|c|c|c|}
\hline & STRENGTH (S) & WEAKNESS $(W)$ \\
\hline & $\begin{array}{l}\text { 1. telah mengimplementasikan } \\
\text { ISO } 9001 \text { dan ISO } 14001 \\
\text { 2. Telah memperoleh sertifikasi } \\
\text { CPOB dan sertifikat pemetaan } \\
\text { tipe A dari BPOM } \\
\text { 3. Telah bekerjasama "Lisence } \\
\text { Produk" dengan banyak } \\
\text { perusahaan besar di } \\
\text { Indonesia maupun Negara } \\
\text { lain } \\
\text { 4. Market share yang relatif } \\
\text { besar serta brand yang kuat } \\
\text { dan diakui oleh industri } \\
\text { farmasi di Indonesia } \\
\text { 5. Memiliki kinerja keuangan } \\
\text { yang cukup bagus } \\
\text { 6. Memiliki kepedulian thd } \\
\text { lingkungan sekitarnya }\end{array}$ & $\begin{array}{l}\text { 1. ada beberapa kategori } \\
\text { obat yang belum dikuasai } \\
\text { 2. belum ada iklan di media } \\
\text { elektronik sehingga tidak } \\
\text { begitu dikenal publik } \\
\text { 3. Teknologi yang ada belum } \\
\text { dipergunakan secara } \\
\text { maksimal dan terintegrasi } \\
\text { 4. Management masih } \\
\text { dikuasai oleh keluarga dan } \\
\text { secara konvensional } \\
\text { 5. Jaringan distribusi belum } \\
\text { luas }\end{array}$ \\
\hline OPPORTUNITIES (O) & SO STRATEGIS & WO STRATEGIS \\
\hline
\end{tabular}


1. Kondisi perekonomian yang membaik sehingga meningkatkan daya beli masyarakat

2. Adanya permintaan atau kebutuhan tertentu yang selama ini belum dilayani oleh pesaing.

3. Teknologi baru yang memungkinkan produksi / distribusi menjadi lebih efisien/ dapat meningkatkan kualitas produk

4. Adanya peningkatan permintaan terhadap kebutuhan kesehatan

5. Dibukanya jalur distribusi baru
1. Mempertahankan harga, pelayanan dan kualitas di setiap produk yang akan ditawarkan kepada konsumen (S1, S2, O1, O2)

2. Membuat produk herbal/obat generic dengan harga terjangkau $(\mathrm{S} 3, \mathrm{O} 3)$

3. Meningkatkan usaha untuk penetrasi pasar di dalam dan diluar Indonesia(S5,S4,O4)

4. Membuat layanan masyarakat tentang perlunya kesehatan $(\mathrm{S} 6, \mathrm{O} 5)$
1. Meningkatkan utilisasi kapasitas varian $(\mathrm{W} 1,01)$

2. Perluasan distribusi obatobatan langsung ke konsumen (W2,O2)

3. Pemanfaatan TI lebih maksimal untuk produksi, marketing dan keuangan (W3,O3)

4. Dapat masuk ke pasar saham sehingga pengembangan usaha lebih leluasa(W4, W5, O4, O5)

\begin{tabular}{|c|c|c|}
\hline THREATS (T): & ST STRATEGIS & WT STRATEGIS \\
\hline $\begin{array}{l}\text { 1. } \begin{array}{l}\text { Munculnya persaing baru } \\
\text { dan produk dalam kategori } \\
\text { obat yang sama }\end{array} \\
\text { 2. Maraknya perdagangan obat } \\
\text { palsu di Indonesia sehingga } \\
\text { harga obat sulit dikontrol } \\
\text { 3. Terjadi krisis financial yang } \\
\text { menurunkan daya beli } \\
\text { 4. peraturan perundangan } \\
\text { pemerintah yang } \\
\text { menetapkan tambahan biaya } \\
\text { distribusi obat generik } \\
\text { 5. perubahan sosial yang } \\
\text { kurang menguntungkan bagi } \\
\text { perusahaan }\end{array}$ & 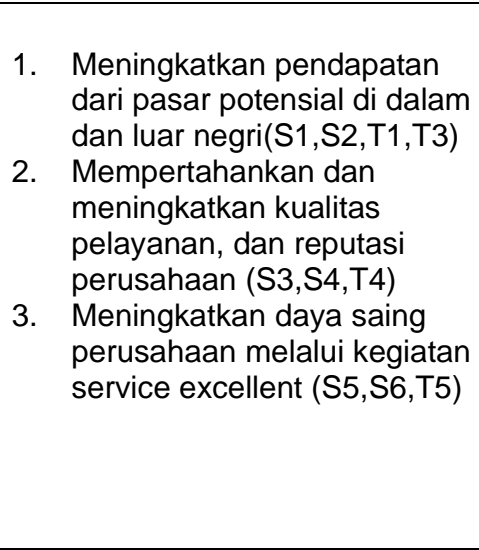 & $\begin{array}{l}\text { 1. Meningkatkan efisiensi } \\
\text { dari biaya operasi } \\
\text { perusahaan (W1, T1) } \\
\text { 2. Peka terhadap perubahan } \\
\text { trend obat yang disukai } \\
\text { oleh pasar (W2,W5, T2, } \\
\text { T3) } \\
\text { 3. Meningkatkan kualitas } \\
\text { dan pemberian pelatihan } \\
\text { secara berkala bagi SDM } \\
\text { (W3, T4) } \\
\text { 4. Memberikan penghargaan } \\
\text { bagi karyawan berprestasi } \\
\text { (W4, T5) }\end{array}$ \\
\hline
\end{tabular}

\subsection{Analisis BSC dan CSF}

Dari analisis Balance Score Card [6] dan analisis Critical Success Factor maka dapat dikonsolidasikan menjadi dalam sebuah kerangka kerja yang harus diperhatikan dan dilakukan penanganan secara serius dalam perspektif keuangan, perspektif pelayanan konsumen. perspektif bisnis internal, perspektif pertumbuhan dan pembelajaran (learning and growth) dan persfektif Sumber Daya Manusia(Human Resource) seperti pada Tabel 2, Tabel 3, Tabel 4 dan Tabel 5 dibawah ini :

Tabel 2. Perspektif Keuangan PT MF

\begin{tabular}{|c|c|c|c|}
\hline \multicolumn{4}{|c|}{ Perspektif Keuangan } \\
\hline Objektif & Pengukuran & Action (CSF) & IS Required \\
\hline $\begin{array}{l}\text { Peningkatan } \\
\text { Pendapatan } \\
\text { (Revenue) }\end{array}$ & $\begin{array}{ll}\text { a. } & \text { memperbesar profit } \\
& \text { margin } \\
\text { b. } & \text { menekan biaya } \\
& \text { pokok penjualan } \\
\text { c. } & \text { menekan biaya } \\
& \text { operasional untuk } \\
& \text { meningkatkan } \\
\text { penjualan }\end{array}$ & $\begin{array}{ll}\text { a. } & \text { promosi dan } \\
\text { meningkatkan } \\
\text { layanan penjualan } \\
\text { b. melakukan efesiensi } \\
\text { biaya operasional }\end{array}$ & $\begin{array}{l}\text { Marketing } \\
\text { Information } \\
\text { System }\end{array}$ \\
\hline $\begin{array}{l}\text { Memperoleh } \\
\text { penilaian } \\
\text { Kinerja } \\
\text { Keuangan } \\
\text { yang baik }\end{array}$ & $\begin{array}{l}\text { a. } \\
\text { atas laporan } \\
\text { keuangan dan } \\
\text { pemberian opininya }\end{array}$ & $\begin{array}{l}\text { a. } \\
\text { mengendalikan dan } \\
\text { penggunalisa } \\
\text { kerja }\end{array}$ & $\begin{array}{l}\text { Budgeting } \\
\text { Information } \\
\text { System }\end{array}$ \\
\hline
\end{tabular}


KOMPUTASI (Jurnal IImiah IImu Komputer dan Matematika)

Vol.16, No.1, Januari 2019, Hal. 227 - 234

P-ISSN: 1693-7554, E-ISSN: 2654-3990

https://journal.unpak.ac.id/index.php/komputasi

\begin{tabular}{|c|c|c|}
\hline & $\begin{array}{l}\text { b. asumsi modal } \\
\text { promosi yang akan } \\
\text { dikeluarkan bagi } \\
\text { konsumen }\end{array}$ & $\begin{array}{l}\text { b. menyeimbangkan } \\
\text { antara budget, } \\
\text { aktivitas serta } \\
\text { lauching produk }\end{array}$ \\
\hline
\end{tabular}

Tabel 3. Perspektif Pelayanan Pelanggan PT MF

\begin{tabular}{|l|l|l|l|}
\hline \multicolumn{5}{|c|}{ Perspektif Pelayanan Konsumen } \\
\hline \multicolumn{1}{|c|}{ Objektif } & \multicolumn{1}{|c|}{ Pengukuran } & Action (CSF) & IS Required \\
\hline Meningkatkan & a. pemanfaatan media & a. mempercepat & Customer \\
kualitas & elektronik maupun & proses produksi & Relationship \\
pelayanan & cetak untuk & sehingga terjadi & Information \\
& berkomunikasi dan & keseimbangan & System \\
& menyampaikan & antara permintaan & \\
& informasi produk & dan pemenuhan & \\
& b. memacu & kebutuhan obat- & \\
& pertumbuhan & obatan & \\
& jumlah konsumen & b. memacu & \\
& serta meminimalkan & peningkatan jumlah & \\
& jumlah keluhan & pelanggan baru & \\
& konsumen & serta meminimalkan & \\
& & jumlah keluhan & \\
& & konsumen & \\
& &
\end{tabular}

Tabel 4. Perspektif Proses Bisnis Internal PT MF

\begin{tabular}{|c|c|c|c|}
\hline \multicolumn{4}{|c|}{ Perspektif Proses Bisnis } \\
\hline Objektif & Pengukuran & Action (CSF) & IS Required \\
\hline $\begin{array}{l}\text { Meningkatkan } \\
\text { efektifitas } \\
\text { operasional } \\
\text { perusahaan }\end{array}$ & $\begin{array}{l}\text { a. standar operasional } \\
\text { perusahaan yang } \\
\text { baku } \\
\text { b. kecepatan proses } \\
\text { pelayanan } \\
\text { c. kecepatan } \\
\text { penanganan keluhan } \\
\text { konsumen }\end{array}$ & $\begin{array}{ll}\text { a. } & \text { menciptakan } \\
\text { standarisasi } \\
\text { pengiriman } \\
\text { b. } \\
\text { pelayanan serta } \\
\text { penanganan } \\
\text { keluhan } \\
\text { konsumen } \\
\text { c. membuat report } \\
\text { tentang kegiatan } \\
\text { operasional bisnis }\end{array}$ & $\begin{array}{l}\text { Distributor } \\
\text { Information } \\
\text { System }\end{array}$ \\
\hline
\end{tabular}

Tabel 5. Perspektif Pertumbuhan dan Pembelajaran PT MF

\begin{tabular}{|c|c|c|c|}
\hline \multicolumn{4}{|c|}{ Perspektif Pertumbuhan dan Pembelajaran } \\
\hline Objektif & Pengukuran & Action (CSF) & IS Required \\
\hline $\begin{array}{l}\text { Memiliki sistem } \\
\text { dan prosedur } \\
\text { yang sesuai } \\
\text { dengan } \\
\text { kebutuhan }\end{array}$ & $\begin{array}{l}\text { Jumlah review } \\
\text { terhadap } \\
\text { efektivitas SOP }\end{array}$ & 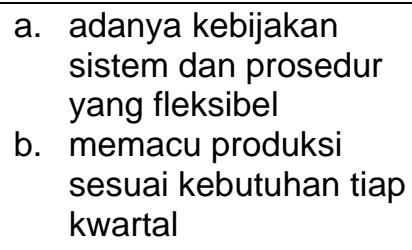 & $\begin{array}{l}\text { Decision } \\
\text { Support } \\
\text { Information } \\
\text { System }\end{array}$ \\
\hline $\begin{array}{l}\text { Memiliki } \\
\text { struktur } \\
\text { organisasi yang } \\
\text { efektif }\end{array}$ & $\begin{array}{l}\text { Jumlah evaluasi } \\
\text { terhadap } \\
\text { efektivitas } \\
\text { organisasi }\end{array}$ & $\begin{array}{l}\text { a. pelatihan dan } \\
\text { kompetensi karyawan } \\
\text { b. memberikan } \\
\text { penghargaaan dan } \\
\text { hukuman bagi SDM } \\
\text { nya }\end{array}$ & $\begin{array}{l}\text { HRD } \\
\text { Information } \\
\text { System }\end{array}$ \\
\hline
\end{tabular}

Perencanaan Strategis Sistem Informasi untuk Meningkatkan Proses Bisnis Perusahaan Farmasi (Julia Ratna Wulan Skawanti) 


\subsection{Analisis Aplikasi yang diproritaskan}

1. Aplikasi HRD Information System

Aplikasi yang perlu dikembangkan dalam mengolah data secara integral dengan data operasional dan keuangan serta pencatatan kehadiran. Integrasi dengan sistem aplikasi keuangan menjadikan lebih memudahkan dalam proses analisis terpadu antara alokasi budget dan realisasi SDM terutama bagi penilaian reward and punishment[7]. SI berbasis web akan memberikan fitur lebih sempurna untuk aplikasi tersebut.

2. Aplikasi Distributor Information System

Aplikasi ini tersedia pada distributor yang telah bekerjasama dengan perusahaan fungsinya untuk pengolahan data transaksi penjualan secara terintegrasi dengan kantor pusat. Menggunakan fitur Structure Query Languange, sehingga efektivitas proses dan integrasi data dapat lebih terjamin. Aplikasi ini merupakan aplikasi strategik perusahaan yang sistem desainnya sangat unik dan perlu di jaga confidentiality sebagai core system

\subsection{Analisis strategis yang diproritaskan}

Aplikasi strategis inovasi proses operasional untuk menggantikan fungsi manusia dalam melaksanakan pekerjaan rutin dan terprogram (clerical). Dengan demikian memungkinkan penurunan biaya operasional dan juga harga jual produk. Hal tersebut untuk mendukung peningkatan value chain dan untuk efektivitas serta efisiensi operasional. Seperti dalam Tabel 6 di bawah ini:

Tabel 6. Prioritas Aplikasi PT MF yang akan dibangun

\begin{tabular}{|c|c|c|}
\hline Perspektif & Aplikasi & Fungsi \\
\hline \multirow[t]{2}{*}{ Keuangan } & $\begin{array}{l}\text { Marketing } \\
\text { Information } \\
\text { System }\end{array}$ & $\begin{array}{l}\text { Memperbesar profit margin serta menekan biaya } \\
\text { operasional dan meningkatkan penjualan }\end{array}$ \\
\hline & $\begin{array}{l}\text { Budgeting } \\
\text { Information } \\
\text { System }\end{array}$ & $\begin{array}{l}\text { Asumsi modal promosi yang akan dikeluarkan bagi } \\
\text { konsumen }\end{array}$ \\
\hline $\begin{array}{l}\text { Pelayanan } \\
\text { Konsumen }\end{array}$ & $\begin{array}{l}\text { Customer } \\
\text { Relationship } \\
\text { Information } \\
\text { System }\end{array}$ & $\begin{array}{l}\text { 1. CRM bagi } \\
\text { a. dokter : memberikan promosi bagi pelatihan } \\
\text { dan pembinaan dokter potensial } \\
\text { b. rumah sakit : memberikan tambahan fasilitas } \\
\text { yg dibutuhkan } \\
\text { c. instansi : memfasilitasi kegiatan yang } \\
\text { dilakukan oleh instransi tersebut } \\
\text { d. distributor : program discount yg saling } \\
\text { menguntungkan } \\
\text { 2. Meminimalkan jumlah keluhan konsumen dan } \\
\text { Promosi produk yang dihasilkan }\end{array}$ \\
\hline Perspektif & Aplikasi & Fungsi \\
\hline $\begin{array}{l}\text { Proses Bisnis } \\
\text { Internal }\end{array}$ & $\begin{array}{l}\text { Distributor } \\
\text { Information } \\
\text { System }\end{array}$ & $\begin{array}{l}\text { Untuk membantu optimalisasi kegiatan produksi } \\
\text { agar tidak ada kelebihan produksi pada periode } \\
\text { tertentu serta terintegrasi dengan SI distributor }\end{array}$ \\
\hline \multirow[t]{2}{*}{$\begin{array}{l}\text { Pertumbuhan } \\
\text { dan } \\
\text { Pembelajaran }\end{array}$} & $\begin{array}{l}\text { Decision } \\
\text { Support } \\
\text { Information } \\
\text { System } \\
\end{array}$ & $\begin{array}{l}\text { Membantu para eksekutif dalam pengambilan } \\
\text { keputusan terutama pada proses produksi sehingga } \\
\text { tidak ada kelebihan produksi }\end{array}$ \\
\hline & $\begin{array}{l}\text { HRD } \\
\text { Information } \\
\text { System }\end{array}$ & $\begin{array}{l}\text { 1. Untuk meningkatkan profesionalisme karyawan } \\
\text { sehingga kinerja akan meningkat }\end{array}$ \\
\hline
\end{tabular}




\begin{tabular}{|l|l|l|}
\hline & $\begin{array}{c}\text { 2. } \\
\text { Data pemberian penghargaan bagi karyawan } \\
\text { berprestasi dan peringatan bagi karyawan } \\
\text { bermasalah }\end{array}$ \\
\hline
\end{tabular}

\subsection{Roadmap Pengembangan Aplikasi}

Dalam mengembangakan aplikasi yang diprioritaskan dilakukan beberapa tahap seperti Gambar 1 di bawah ini:

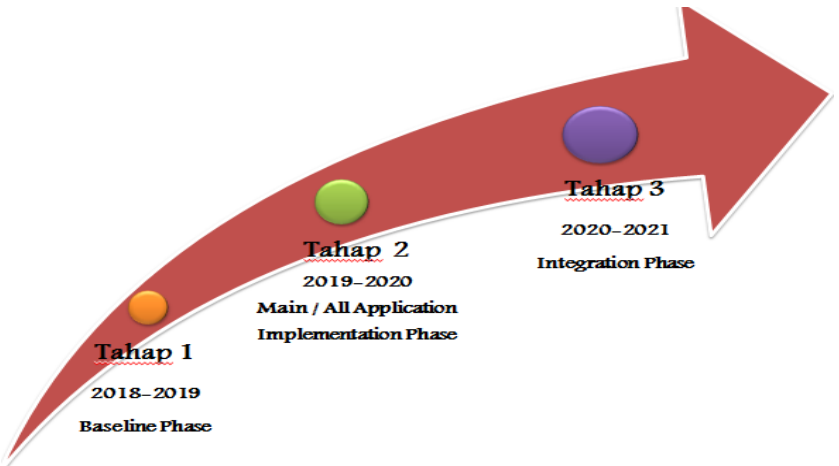

Gambar 1. Roadmap Aplikasi PT MF

\section{Tahap 1 Baselined Phase}

Pada tahap ini aplikasi sederhana yang akan dibangun yaitu Marketing Information System, Budgeting Information System, Decision Support Information System, Customer Relationship Information System dan Distributor Information System.

\section{Tahap 2 Main/ All Application Implementation Phase}

Aplikasi yang saling berintegrasi sehingga dapat menunjang kegiatan bisnis. Adapun aplikasi yang sudah terintegrasi adalah Marketing Information System, Budgeting Information System, Distributor Information System sertaDecision Support Information System. Aplikasi Customer Relationship Information System dan sudah dapat bertintegrasi dengan website PT MF.

\section{Tahap 3 Integration Phase}

Tahap dimana semua aplikasi sudah terintegrasi dalam mengelola proses bisnisnya. Aplikasi yang dibangun diharapkan dapat meningkatkan kinerja dari kegiatan bisnis, memberikan pelayanan yang maksimal kepada konsumen sehingga SI dan TI menjadi ujung tombak untuk setiap stakeholder perusahaan dalam mengambil keputusan yang bertujuan untuk meningkatkan kemajuan dan pendapatan perusahaan.

\section{Kesimpulan}

Berdasarkan hasil analisis dan perumusan strategi sistem informasi PT MF maka dapat disimpulkan bahwa PT MF sebagai perusahaan farmasi telah memiliki prosedur sistem sebagai acuan untuk operasional proses bisnis dalam rangka meningkatkan efisiensi dan efektifitas perusahaannya. Sistem informasi yang dibutuhkan dibagi kedalam empat perspektif, yaitu keuangan, konsumen, bisnis internal serta pertumbuhan dan pengembangan. Penerapan aplikasi terbagi menjadi tiga tahap dimulai dari tahun 2018 hingga tahun 2021. Evaluasi proses bisnis saat ini memperlihatkan perlunya penerapan sistem informasi berbasis komputer yang terintegrasi bagi semua divisi sehingga dapat mendukung proses bisnis perusahaan.

Dalam rangka meningkatkan kinerja internal perusahaan, kepuasan konsumen serta peningkatan efektifitas dan efisiensi perusahaan maka diperlukan beberapa peningkatan lain seperti perencanaan strategis SI secara tepat dan berkelanjutan. Meningkatkan kualitas sumber daya manusia dengan memberikan reward dan punishment serta dapat melihat potensi dari setiap sumber daya manusia sehingga dapat meningkatkan kinerjanya. Pada lingkungan eksternal, mampu bersaing dengan competitor lain, mampu membaca pasar yang sedang trend melakukan promosi selain di media massa juga di media digital, memperluas mitra kerjasama 
dan memperluas wilayah pemasaran serta membuka distributor sendiri agar laba tidak dibagi dengan perusahaan lain serta dapat membuka lapangan kerja baru.

\section{Referensi}

[1] Ward, J. Peppard,J. 2003. Strategic Planning For Information Strategy, $3^{\text {rd }}$ ed. John willey \& sons, LTD, England

[2] Amaliah, N., Herawati, Y. T., Witcahyo, E., Administrasi, B., \& Masyarakat, F. K. 2017. Analisis SWOT di Instalasi Gawat Darurat ( IGD ) Rumah Sakit Fathma Medika Gresik untuk Meningkatkan Kunjungan Tahun 2016 SWOT Analysis in the Emergency Room ( ER ) of Fathma Medika Hospital Gresik in Order to Increasing Visits 2016. Jurnal Pustaka Kesehatan. 5(2), 223-230.

[3] Kaplan, R. S. and Norton, D. P. 1992. The Balanced Scorecard-Measures that drives performance", Harvard business review, Jan-Feb 1992, p. 71-79

[4] Rangkuti, Freddy. 2005. Analisis SWOT Teknik Membedah Kasus Bisnis. PT Gramedia Pustaka Utama, Jakarta

[5] Kusumawardani, N.D., Mursityo, Y.T., Rokhmawati, R.I. 2019. Evaluasi Critical Success Factors Pada Implementasi Sistem Informasi Supply Chain Management (ALISTA) Menggunakan Metode Dematel Pada PT Telkom Akases Malang. Jurnal Pengembangan Teknologi Informasi dan IImu Komputer. 3(5), 4316-4326.

[6] Sari, M. 2016. Perancangan Balanced Scorecard sebagai Pengukuran Kinerja pada PT Asuransi MSIG Indonesia. Jurnal Riset Akuntansi dan Bisnis. 15(1), 140-153.

[7] Aryane. 2015. Pengaruh Penerapan Pengukuran Kinerja Berbasis Balanced Scored Terhadap Kinerja Manajer (Studi Kasus pada Yayasan Pendidikan Telkom). 2(3), 23812393.

[8] Darmanto, E. 2015. Analisa Optimalisasi Bahasa Sql Berdasarkan Relational Algebra Pada Kasus Rekapitulasi Mahasiswa Layak Wisuda. Simetris : Jurnal Teknik Mesin, Elektro Dan IImu Komputer, 6(2), 405. https://doi.org/10.24176/simet.v6i2.479. 